\title{
Article \\ Outcomes and Prognosis of Non-Elderly Patients with Brain Metastases-A Prospective Cohort Incorporating Individualized Assessment of Heart Rate Variability
}

\author{
Yu-Ming Wang ${ }^{1,2,3} \mathbb{D}$, Jen-Yu Cheng ${ }^{2} \mathbb{D}$, Chong-Jong Wang ${ }^{2}$, Shu-Shya Hseu ${ }^{4}$ and Eng-Yen Huang ${ }^{2,3, *}$ \\ 1 Department \& Institute of Physiology, National Yang Ming Chiao Tung University, Taipei 11221, Taiwan; \\ scorpion@cgmh.org.tw \\ 2 Department of Radiation Oncology \& Proton and Radiation Therapy Center, Kaohsiung Chang Gung \\ Memorial Hospital, Chang Gung University College of Medicine, Kaohsiung 83301, Taiwan; \\ york480@cgmh.org.tw (J.-Y.C.); cjw1010@cgmh.org.tw (C.-J.W.) \\ 3 School of Traditional Chinese Medicine, Chang Gung University, Taoyuan 33302, Taiwan \\ 4 Department of Anesthesiology, Taipei Veterans General Hospital, Taipei 11217, Taiwan; \\ sshseu@vghtpe.gov.tw \\ * Correspondence: hey1200@cgmh.org.tw; Tel.: +886-7-731-7123 (ext. 7000)
}

check for updates

Citation: Wang, Y.-M.; Cheng, J.-Y.; Wang, C.-J.; Hseu, S.-S.; Huang, E.-Y. Outcomes and Prognosis of

Non-Elderly Patients with Brain Metastases-A Prospective Cohort Incorporating Individualized Assessment of Heart Rate Variability. J. Pers. Med. 2021, 11, 1049. https:// doi.org/10.3390/jpm11111049

Academic Editor: Carlo Palombo

Received: 31 July 2021

Accepted: 17 October 2021

Published: 20 October 2021

Publisher's Note: MDPI stays neutral with regard to jurisdictional claims in published maps and institutional affiliations.

Copyright: (c) 2021 by the authors. Licensee MDPI, Basel, Switzerland. This article is an open access article distributed under the terms and conditions of the Creative Commons Attribution (CC BY) license (https:// creativecommons.org/licenses/by/ $4.0 /)$.

\begin{abstract}
Outcomes and prognostic factors among patients with brain metastases (BM) have been widely studied, but seldom for the non-elderly. Heart rate variability (HRV) is a physiological phenomenon and has been shown as a survival prognostic factor in cancer patients. This study aimed to evaluate the outcomes and prognosis among non-elderly BM patients with the incorporation of HRV analysis. Forty non-elderly BM patients treated using whole brain radiotherapy (WBRT) were studied from January 2010 prospectively with 5-min electrocardiography (ECG) recordings. Individualized HRV was generated by the ECG, and the time domain HRV index SDNN was chosen for survival analysis. The median overall survival (OS) for the entire group was 6.21 months. Univariate analysis revealed that a KPS $<80(p=0.019)$ and an SDNN $<10 \mathrm{~ms}(p=0.007)$ demonstrated statistical significance for OS; multivariate analysis confirmed that a KPS $<80(p=0.004 ; \mathrm{HR}=3.060$, $\mathrm{CI}=1.437-6.517)$ and an SDNN $<10 \mathrm{~ms}(p=0.010 ; \mathrm{HR}=2.664, \mathrm{CI}=1.262-5.624)$ were independent prognostic factors. Prospective studies for risk stratification among non-elderly BM patients based on our results are warranted to validate our findings.
\end{abstract}

Keywords: brain metastases; non-elderly; age; heart rate variability; radiotherapy; prognosis

\section{Introduction}

Brain metastases (BM) frequently occur in patients with advanced cancer, and are the most common intracranial tumor, estimated to be 10 times more frequent than primary brain tumors [1,2]. Although different treatment modalities have been reported, the outcome is still unsatisfactory [3]. Previous large prospective studies demonstrated that age is an independent survival prognostic factor in BM patients. Patients with a younger age have better survival compared to the elderly [4-7]. With emerging novel modalities of therapeutic options, non-elderly BM patients, especially those with longer life expectancies, should be considered differently and treated more aggressively, as they are more tolerant to treatments [8-10]. Nieder et al. found that survival prognostic factors in non-elderly BM patients differ from older patients [11]. Nevertheless, studies focusing on outcomes and prognosis among non-elderly BM patients still need more investigation.

Heart rate variability (HRV) is a physiologic phenomenon that is predominantly regulated by the vagus nerve [12]. It represents the complexity of the physiological system that controls homeostasis. With the standardized method for recording and measuring, HRV is well-documented and can be assessed in clinics non-invasively [13]. Subjects with a lower HRV, which can be a surrogate of impaired vagal function, are at higher risk 
for cancer-prone environment and with higher risk for life threatening cardio-cerebral circulation events [14-16]. In addition to the theoretical background, clinical use of HRV have also been widely studied. The correlation between HRV and the severity of disease, such as acute myocardial infarction, heart failure, diabetes mellitus, and cancer survival, has been published the previous literature. Patients with lower HRV did predict inferior outcomes and survival [17-21]. However, the application of this finding for non-elderly $\mathrm{BM}$ patients remains unclear.

To understand and stratify the risk among non-elderly BM patients and to incorporate the novel factor HRV, this study was conducted to further investigate this group of patients.

\section{Materials and Methods}

\subsection{Participants}

This prospective study began in January 2010, and our Institutional Review Board approved all protocols (98-3760B). The recruited BM patients were those who underwent palliative whole brain radiotherapy (WBRT) in our department and agreed to participate in HRV analysis. Patients with a history of central nervous system or thoracic surgery, or with underlying arrhythmia, or actively taking medications that could influence HRV were excluded. Before entering the study, the participants' clinical history, previous cancer treatments, and radiological factors were recorded; and all participants also underwent a comprehensive physical examination before the start of treatment. An electrocardiogram (ECG) was performed during the initial evaluation for HRV analysis. To assess the clinical impact of HRV in non-elderly patients, defined as being aged under 65 years old, data from patients who met this age definition were used in the following analysis.

\subsection{ECG Signal Processing for $H R V$}

The HRV analysis protocol has been reported previously [19], summarized as follows. Five-minute digitalized ECG was acquired from all patients on the same day or one day before WBRT simulation in a quiet room in supine position. The $\mathrm{R}$ peaks of each valid QRS complex were labelled for processing for HRV using the standardized HRV analytic method [13]. Based on previously published results, the standard deviation of normalto-normal intervals (SDNN), the global HRV index, was used as a prognostic factor for survival analysis.

\subsection{Radiotherapy and Follow-Up}

As this study protocol was not designed to change the standard care, all patients were treated following our public health insurance policy for BM patients using WBRT, with selected patients receiving an additional local boost (LB). Patients were immobilized with a thermoplastic cast in supine position and simulated by a CT simulator with a $3.75 \mathrm{~mm}$ slice thickness. WBRT fields were designed as conventional bilateral opposed helmet fields. Patients were irradiated using 6 or 15 megavolt photons at a dose of 30 to 37.5 Gy in 10 to 15 daily fractions, with 5 fractions per week. Administrating an additional LB to the gross intracranial tumors was suggested for selected patients following WBRT as our routine practice. Generally, patients with good performance whose intracranial tumor were larger than $2 \mathrm{~cm}$ in diameter were suggested to receive local boost course. LB was delivered using intensity-modulated radiotherapy for an additional 10 to $14 \mathrm{~Gy}$ in 5 to 7 daily fractions targeting only the gross intracranial lesions. After completing the RT course, patients were followed up in a 1-to-2-month intervals. Brain images were performed regularly until their death. For those patients who were not able to be present at our out-patient clinic, telephone contact was used instead.

\subsection{Study Endpoints and Statistics}

The primary endpoint for this study was overall survival (OS); the time of survival was calculated from the day of the ECG recording to the date of death or the last follow-up. All known clinical factors, radiological factors [4-7], comorbidities such as diabetes mellitus 
and hypertension, and the HRV index SDNN were used as prognostic factors for the study. IBM SPSS Statistics version 20 (IBM, Armonk, NY, USA) was used for the following calculation. Factors among each group were compared using Chi-square or Fisher's exact test for categorical variables; an independent $t$-test was used for comparison between continuous variables. OS was analyzed by the Kaplan-Meier method. Prognostic factors were compared using the log-rank test; Cox's proportional hazard regression method was used for multivariate analysis, and variables that reached $p<0.1$ in univariate analysis were put into examination. Significant differences were met when $p<0.05$.

\section{Results}

\subsection{Characteristics of the Participants}

A total of $40 \mathrm{BM}$ patients aged under 65 prospectively recruited into our study were retrospective analyzed. The median age of this cohort was 57 , and $60 \%$ of these patients were diagnosed with non-small cell carcinoma of the lungs (NSCLC). Most patients had extracranial metastases and did not have the primary origin under control when they were confirmed as having BM. Seventy-five patients had more than three intracranial lesions, and more than $40 \%$ of our patients had a volume of the largest intracranial lesion of more than $5 \mathrm{~cm}^{3}$. With the relatively young age of these patients, $35 \%$ of them had a KPS of 80 or above. For the HRV index, one third had an SDNN $<10 \mathrm{~ms}$. Based on the most used risk stratification system [4], only one patient met the criterion of RPA I (Table 1).

Table 1. Demographic data of all non-elderly brain metastasis patients.

\begin{tabular}{|c|c|c|}
\hline Parameter & $n$ & $\%$ \\
\hline \multicolumn{3}{|l|}{ Gender } \\
\hline Female & 24 & $60.0 \%$ \\
\hline Male & 16 & $40.0 \%$ \\
\hline \multicolumn{3}{|l|}{ Age } \\
\hline$<40$ & 3 & $7.5 \%$ \\
\hline $40-49$ & 6 & $15.0 \%$ \\
\hline $50-59$ & 17 & $42.5 \%$ \\
\hline $60-64$ & 14 & $35.0 \%$ \\
\hline \multicolumn{3}{|l|}{ KPS } \\
\hline $40-50$ & 9 & $22.5 \%$ \\
\hline $60-70$ & 17 & $42.5 \%$ \\
\hline $80-90$ & 14 & $35.0 \%$ \\
\hline \multicolumn{3}{|c|}{ Extracranial metastases } \\
\hline Without & 8 & $20.0 \%$ \\
\hline With & 32 & $80.0 \%$ \\
\hline \multicolumn{3}{|l|}{ Primary Status } \\
\hline Not controlled & 35 & $87.5 \%$ \\
\hline Controlled & 5 & $12.5 \%$ \\
\hline \multicolumn{3}{|c|}{ Number of Metastasis } \\
\hline 1 & 4 & $10.0 \%$ \\
\hline $2-3$ & 6 & $15.0 \%$ \\
\hline$>3$ & 30 & $75.0 \%$ \\
\hline \multicolumn{3}{|c|}{ Volume of the largest lesion } \\
\hline$<5 \mathrm{~cm}^{3}$ & 23 & $57.5 \%$ \\
\hline $5-13 \mathrm{~cm}^{3}$ & 9 & $22.5 \%$ \\
\hline$\geq 13 \mathrm{~cm}^{3}$ & 8 & $20.0 \%$ \\
\hline \multicolumn{3}{|l|}{ Primary } \\
\hline NSCLC & 24 & $60.0 \%$ \\
\hline SCLC & 3 & $7.5 \%$ \\
\hline Breast & 7 & $17.5 \%$ \\
\hline Others & 6 & $15.0 \%$ \\
\hline \multicolumn{3}{|l|}{$\mathrm{DM}$} \\
\hline With & 6 & $15.0 \%$ \\
\hline Without & 34 & $85.0 \%$ \\
\hline
\end{tabular}


Table 1. Cont.

\begin{tabular}{lcc}
\hline Parameter & $n$ & $\%$ \\
\hline HTN & 10 & \\
With & 30 & $75.0 \%$ \\
$\quad$ Without & & \\
SDNN & 13 & $32.5 \%$ \\
$\quad<10 \mathrm{~ms}$ & 27 & $67.5 \%$ \\
$\geq 10 \mathrm{~ms}$ & & $2.5 \%$ \\
RPA Class & 1 & $70.0 \%$ \\
I & 28 & $27.5 \%$ \\
II & 11 & \\
III & & \\
\hline Abb
\end{tabular}

Abbreviations: KPS: Karnofsky performance status; NSCLC: non-small cell lung cancer; SCLC: small cell lung cancer; DM: diabetes mellitus; HTN: hypertension; SDNN: standard deviation of normal-to-normal intervals.

For the following analysis, an SDNN of $10 \mathrm{~ms}$ was chosen as the cutoff value [19]. There was no significant difference among each prognostic factor between patients with an SDNN $<10 \mathrm{~ms}$ and an SDNN $\geq 10 \mathrm{~ms}$ (Table 2).

Table 2. Comparison of parameters between SDNN groups.

\begin{tabular}{|c|c|c|c|}
\hline & $\mathrm{SDNN}<10 \mathrm{~ms}$ & $\mathrm{SDNN} \geq 10 \mathrm{~ms}$ & $p$ Value \\
\hline Age & $57.23 \pm 6.60$ & $52.52 \pm 8.56$ & 0.089 \\
\hline \multicolumn{4}{|l|}{ Gender } \\
\hline Female & 6 & 18 & \multirow[b]{2}{*}{0.305} \\
\hline Male & 7 & $\begin{array}{c}10 \\
9\end{array}$ & \\
\hline \multicolumn{4}{|l|}{ KPS } \\
\hline$<80$ & 10 & 16 & \multirow{2}{*}{0.316} \\
\hline$\geq 80$ & 3 & 11 & \\
\hline \multicolumn{4}{|c|}{ Extracranial metastases } \\
\hline Without & 2 & 6 & \multirow{2}{*}{1.000} \\
\hline With & 11 & 21 & \\
\hline \multicolumn{4}{|l|}{ Primary status } \\
\hline Not controlled & 11 & 24 & \multirow[b]{2}{*}{1.000} \\
\hline Controlled & 2 & 3 & \\
\hline \multicolumn{4}{|c|}{ Number of metastases } \\
\hline$\leq 3$ & 4 & 6 & \multirow{2}{*}{0.700} \\
\hline$>3$ & 9 & 21 & \\
\hline \multirow{2}{*}{\multicolumn{4}{|c|}{$\begin{array}{l}\text { Volume of the largest } \\
\text { lesion }\end{array}$}} \\
\hline & & & \\
\hline$\leq 5 \mathrm{~cm}^{3}$ & 6 & 17 & \multirow{2}{*}{0.496} \\
\hline$>5 \mathrm{~cm}^{3}$ & 7 & 10 & \\
\hline \multicolumn{4}{|l|}{ Primary } \\
\hline NSCLC & 8 & 16 & \multirow{2}{*}{1.000} \\
\hline Others & 5 & 11 & \\
\hline \multicolumn{4}{|l|}{$\mathrm{DM}$} \\
\hline With & 1 & 5 & \multirow[b]{2}{*}{0.643} \\
\hline Without & 12 & 22 & \\
\hline \multicolumn{4}{|l|}{ HTN } \\
\hline With & 5 & 5 & \multirow{2}{*}{0.246} \\
\hline Without & 8 & 22 & \\
\hline
\end{tabular}

Abbreviations: SDNN: standard deviation of normal-to-normal intervals; KPS: Karnofsky performance status NSCLC: non-small cell lung cancer; SCLC: small cell lung cancer; DM: diabetes mellitus; HTN: hypertension.

\subsection{Treatment Outcomes}

At the time we performed the analysis, three patients were alive. The median followup time of these survivors was 49.74 months. The median OS of the entire groups was 6.21 months, with 3-month, 6-month, and 12-month survival of $62.5 \%, 52.5 \%$, and $34.8 \%$, respectively (Figure 1 ). 


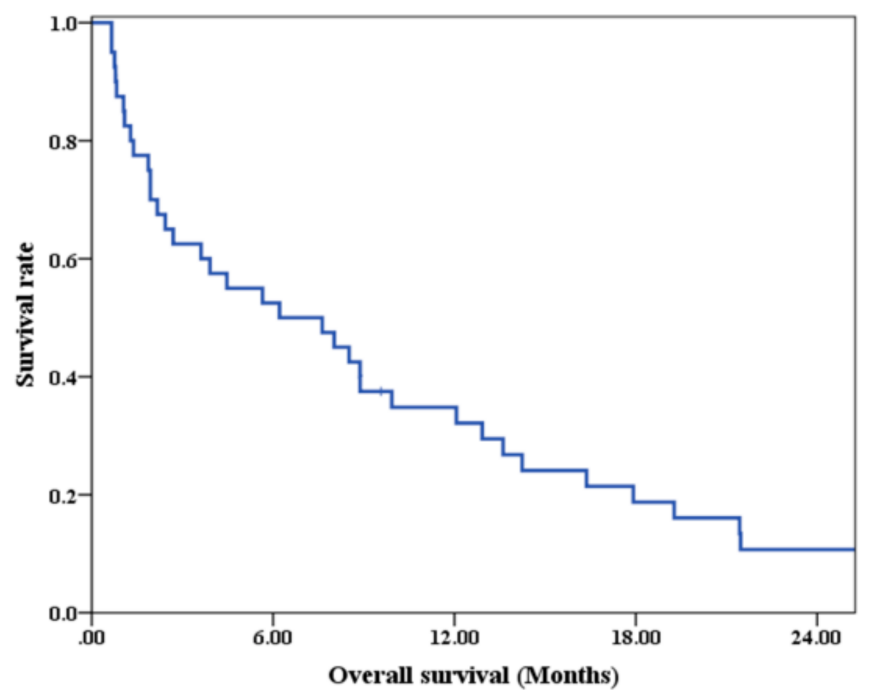

Figure 1. Overall survival of all non-elderly brain metastases patients.

\subsection{Prognostic Factors}

Univariate analysis revealed that the KPS and SDNN were significant prognostic factors for OS (Table 3). The median OS for patients with a KPS $<80$ and $\geqq 80$ were 2.17 and 9.93 months, respectively ( $p=0.019$ ) (Figure 2A). The corresponding median OS for patients with an SDNN $<10 \mathrm{~ms}$ and $\geqq 10$ ms were 2.70 and 8.88 months ( $p=0.007$ ) (Figure $2 \mathrm{~B}$ ).

Table 3. Univariate analysis on overall survival.

\begin{tabular}{|c|c|c|c|c|c|}
\hline \multirow{2}{*}{ Parameters } & \multirow{2}{*}{$n$} & \multicolumn{4}{|c|}{ Overall Survival } \\
\hline & & Median (months) & $3 \mathbf{M}$ & $6 \mathrm{M}$ & $p$ Value \\
\hline All Participant & 40 & 6.21 & $62.5 \%$ & $52.5 \%$ & - \\
\hline \multicolumn{6}{|l|}{ Gender } \\
\hline Female & 24 & 7.63 & $66.7 \%$ & $54.2 \%$ & \multirow{2}{*}{0.420} \\
\hline Male & 16 & 3.62 & $56.3 \%$ & $50.0 \%$ & \\
\hline \multicolumn{6}{|l|}{ KPS } \\
\hline$<80$ & 26 & 2.17 & $42.3 \%$ & $34.6 \%$ & \multirow{2}{*}{0.019} \\
\hline$\geq 80$ & 14 & 9.93 & $100.0 \%$ & $85.7 \%$ & \\
\hline \multicolumn{6}{|l|}{$\begin{array}{l}\text { Extracranial } \\
\text { metastases }\end{array}$} \\
\hline Without & 8 & 12.07 & $87.5 \%$ & $87.5 \%$ & \multirow{2}{*}{0.245} \\
\hline With & 32 & 3.91 & $56.3 \%$ & $43.8 \%$ & \\
\hline \multicolumn{6}{|l|}{ Primary status } \\
\hline Not controlled & 35 & 6.21 & $60.0 \%$ & $51.4 \%$ & \multirow[b]{2}{*}{0.196} \\
\hline Controlled & 5 & 21.47 & $80.0 \%$ & $60.0 \%$ & \\
\hline \multicolumn{6}{|l|}{ Number of } \\
\hline \multicolumn{6}{|l|}{ Metastases } \\
\hline$\leq 3$ & 10 & 6.21 & $70.0 \%$ & $60.0 \%$ & \multirow[b]{2}{*}{0.493} \\
\hline$>3$ & 30 & 5.65 & $60.0 \%$ & $50.0 \%$ & \\
\hline \multirow{2}{*}{\multicolumn{6}{|c|}{$\begin{array}{l}\text { Volume of the } \\
\text { largest lesion }\end{array}$}} \\
\hline & & & & & \\
\hline$\leq 5 \mathrm{~cm}^{3}$ & 23 & 8.52 & $65.2 \%$ & $56.5 \%$ & \multirow{2}{*}{0.949} \\
\hline$>5 \mathrm{~cm}^{3}$ & 17 & 4.47 & $58.8 \%$ & $47.1 \%$ & \\
\hline \multicolumn{6}{|l|}{ Primary } \\
\hline NSCLC & 24 & 8.02 & $62.5 \%$ & $58.3 \%$ & \multirow{2}{*}{0.312} \\
\hline Others & 16 & 3.91 & $62.5 \%$ & $43.8 \%$ & \\
\hline
\end{tabular}


Table 3. Cont.

\begin{tabular}{|c|c|c|c|c|c|}
\hline \multirow{2}{*}{ Parameters } & \multirow{2}{*}{$n$} & \multicolumn{4}{|c|}{ Overall Survival } \\
\hline & & Median (months) & $3 \mathbf{M}$ & $6 \mathrm{M}$ & $p$ Value \\
\hline \multicolumn{6}{|l|}{ DM } \\
\hline With & 6 & 12.92 & $83.3 \%$ & $83.3 \%$ & \multirow{2}{*}{0.515} \\
\hline Without & 34 & 4.47 & $58.8 \%$ & $47.1 \%$ & \\
\hline \multicolumn{6}{|l|}{ HTN } \\
\hline With & 10 & 7.63 & $60.0 \%$ & $60.0 \%$ & \multirow{2}{*}{0.463} \\
\hline Without & 30 & 5.65 & $63.3 \%$ & $50.0 \%$ & \\
\hline \multicolumn{6}{|l|}{ SDNN } \\
\hline$<10 \mathrm{~ms}$ & 13 & 2.70 & $46.2 \%$ & $30.8 \%$ & \multirow{2}{*}{0.007} \\
\hline$\geq 10 \mathrm{~ms}$ & 27 & 8.88 & $70.4 \%$ & $63.0 \%$ & \\
\hline
\end{tabular}

Abbreviations: KPS: Karnofsky performance status; NSCLC: non-small cell lung cancer; DM: diabetes mellitus; HTN: hypertension; SDNN: standard deviation of normal-to-normal intervals.
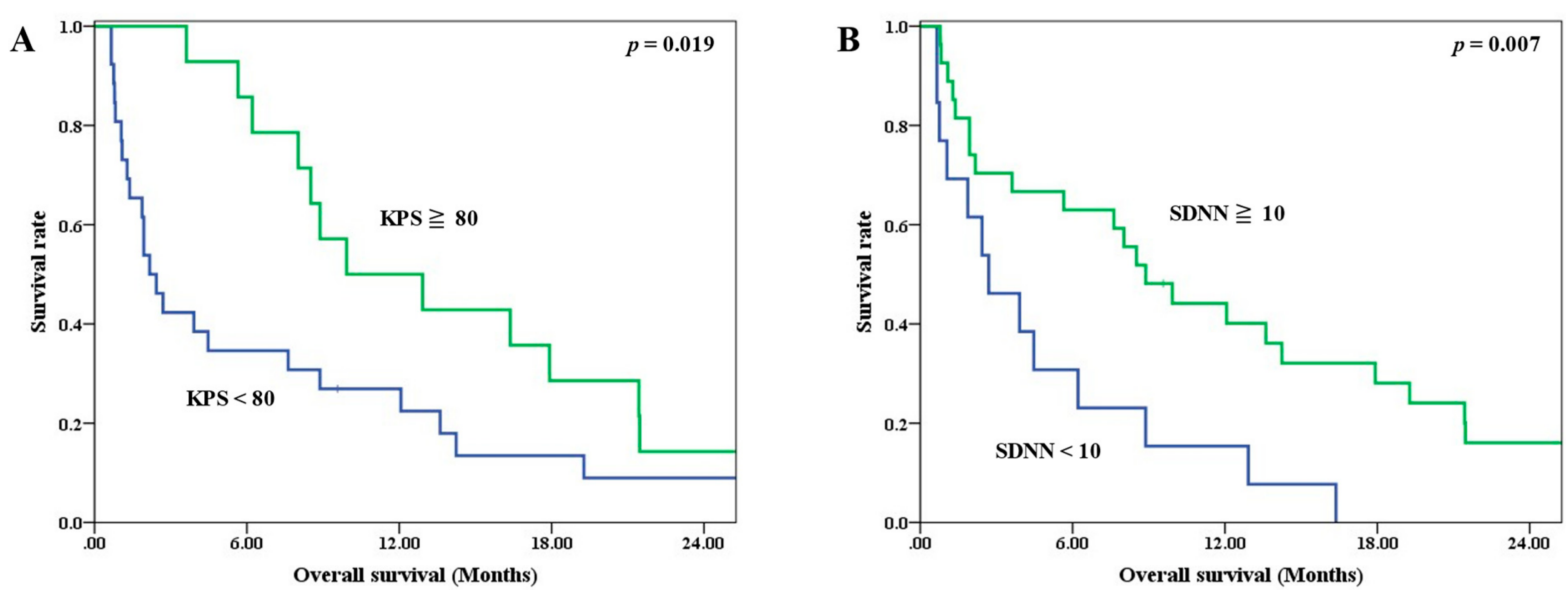

Figure 2. Survival curves stratified by prognostic factors (A) KPS, (B) SDNN.

For multivariate analysis, a KPS of $80(p=0.018$; HR $=2.349, \mathrm{CI}=1.159-4.762)$ and an SDNN of $10 \mathrm{~ms}(p=0.008 ; \mathrm{HR}=2.766, \mathrm{CI}=1.306-5.857)$ were confirmed as independent OS prognostic factors (Table 4). Factors other than the KPS and SDNN did not meet statistical significance.

Table 4. Multivariate analysis on overall survival.

\begin{tabular}{cccc}
\hline \multirow{2}{*}{ Parameters } & \multicolumn{3}{c}{ Overall Survival } \\
\cline { 2 - 4 } & $\boldsymbol{p}$ Value & HR & $\mathbf{9 5 \%}$ CI \\
\hline KPS: $<80$ vs. $\geq 80$ & 0.018 & 2.349 & $1.159-4.762$ \\
SDNN: $<10 \mathrm{~ms}$ vs. $\geq 10 \mathrm{~ms}$ & 0.008 & 2.766 & $1.306-5.857$ \\
\hline
\end{tabular}

Abbreviations: HR: hazard ratio; CI: confidence interval; KPS: Karnofsky performance status; SDNN: standard deviation of normal-to-normal intervals.

\section{Discussion}

Our results demonstrate that the KPS and HRV were independent prognostic factors for OS for BM patients with an age under 65 both by univariate analysis and multivariate analysis. Understanding the prognosis of younger-aged BM patients is of clinical importance. With emerging novel technology, various treatment modalities are available and have been proved to be effective for BM such as surgical resection, stereotactic radiosurgery (SRS), hippocampus-avoidance WBRT, and conventional WBRT. These options could be used alone or in combination, and the treatment choice should be tailored based on expected survival [8]. Previous studies have shown that age is a prognostic factor for survival for BM patients, but few studies have addressed this specific group of non-elderly patients [11]. Although different cutoff values of age have been used, this younger group 
of patients tended to have longer survival than the elderly [4-7], and they are more suitable for aggressive treatment or prospective trials. In this study, age of 65 years was used for defining non-elderly because this value was used in the landmark study conducted by Gasper et al. using WBRT for patients with BM [4]. In addition, De Couck et al. have shown that HRV, particularly the index SDNN, derived from $10 \mathrm{~s}$ ECG can predict survival in cancer patients age under 65 [22]. Our finding of incorporating HRV analysis before treatment starts for better risk stratification is encouraging. To the best of our knowledge, this is the first study in the literature focusing on non-elderly BM patients with assessment of HRV.

The direct mechanism between low HRV and worse prognosis among BM patients is not yet fully understood; however, understanding the underlying control of HRV provided strong support for this correlation. HRV is regulated predominantly by parasympathetic control via the vagus nerve [12,13], and the function of the vagus nerve is associated with systemic tumor progression and prognosis [16,23]. Gidron et al. postulated the model presenting the vagus nerve as the mediator of tumor-to-brain communication [16]. The vagus nerve transmits signals of peripheral inflammation and oxidative stress, both of which are related to the tumorigenesis microenvironment, to the brain, and it also translates the central control from the brain to reduce proinflammation and oxidative stress in the periphery [24,25]. This implies that for patients with impaired vagal function, the brain may lose its ability to modulate systemic cancer progression, which could lead to worse prognosis. This hypothesis had been supported by previous studies regarding the HRV and survival prognosis among cancer patients [23].

In addition to the tumor-to-brain control via the vagus nerve, impaired cardio-cerebral circulation control could be another factor that leads to worse survival. Patients with lower HRV present with attenuated cardiac vagal activity, which leads to impaired regulation of cerebral circulation $[15,26]$. In addition, previous studies also demonstrated that subjects with lower HRV had a substantially higher risk of major cardiac events that could lead to sudden or non-sudden cardiovascular death [14,27]. Taking these together, BM patients with lower HRV were at higher risk for subsequent cardio-cerebral circulation accidents that could lead to sudden or non-sudden deaths even without documented systemic tumor progression.

In present study, HRV was assessed using the index of SDNN, which stands for the standard deviation of the interval lengths between each heartbeat. The SDNN is an index generated from time-domain analysis and represents the global HRV [13]. Several previous studies have shown that the SDNN correlates with survival among cancer patients and different cutoff values have been used among different clinical scenarios [19,21,28-30]. Here, we chose an SDNN of $10 \mathrm{~ms}$ for survival analysis based on previous results of patients with BM [19]. However, as this study focused on a relatively young age of the population, we tested whether a correlation between the SDNN and each factor existed. In addition, multivariate analysis was also conducted to confirm that the SDNN is an independent prognostic factor.

The assessment of HRV is simply from ECG recordings. As ECG is a non-invasive tool, it is good for the clinical setting to evaluate BM patients. However, factors that could influence HRV exist. For instance, medications such as beta-blockers or anti-arrhythmic drugs, the length of ECG recordings for analysis [13], and previous mediastinal irradiation [31] have all been reported. Thus, as a prospective study focusing on the use of HRV, a standardized protocol was used to minimize possible confounding factors for HRV assessment. In addition, 5-min ECGs were recorded and used for analysis as we thought it was more suitable than $24-\mathrm{h}$ recording for radiation oncology outpatient setting and for BM patients.

Performance status has long been used as a survival prognostic factor for BM patients [4-7]. In addition, a retrospective study conducted by Nieder et al. [11] also showed significant survival difference with KPS among young age BM patients by means of univariate analysis. Our results further confirm these findings. In the present study, we tested 
the prognostic significance of performance status not only by means of univariate analysis but also using multivariate analysis. Patients with a KPS of 80 or more had significant longer survival comparing to those with a KPS $<80$, with a hazard ratio of 3.06. Though different values were used by different researchers, evaluating the KPS for non-elderly BM patients is still a powerful tool for risk stratification.

Although patients in this study were of a relatively younger age, the treatment that we used was uniformly WBRT. Needless to say, this treatment could lead to significant neurocognitive impairment [32-34]. The rationale for using WBRT in this study was the reimbursement policy of our National Health Insurance, and it reflects the real-world practice here in our country. According to our reimbursement policy, precise and less harmful treatment such as SRS could only be considered for BM patients with a good performance status, controlled primary tumors, without extracranial metastases, fewer than four intracranial lesions, and lesions with diameter smaller than $3 \mathrm{~cm} \mathrm{[35],} \mathrm{as} \mathrm{all}$ these factors together predict longer expected survival [4-7]. In this study cohort, with all patients being aged under 65 years, only one patient met all these reimbursement criteria, except for the fact that she was diagnosed with multiple intracranial lesions, meaning that the application of SRS was not suitable. Our study was not aimed at testing different treatment methods; however, based on our results, we would suggest that the choice of treatment options for patients with a good KPS and higher HRV should be considered differently, especially for these younger-aged BM patients.

There are several limitations in this study. First, the treatment was uniformly WBRT, and BM patients treated by using other modalities such as surgical resection or SRS were not included. Second, only one patient in this cohort met the criterion of RPA I, meaning that whether our findings can be applied to this group remains unclear. Third, the primary origins of BM were heterogenous, and thus disease-specific outcomes require further investigation.

\section{Conclusions}

The outcomes of non-elderly BM patients treated using WBRT were studied. The results of our small series prospective cohort reveal that the HRV index SDNN, in addition to the KPS, is an independent survival prognostic factor. The risk stratification of life expectancy with the incorporation of HRV is encouraging. Prospective studies based on these results for further investigation are warranted.

Author Contributions: Conceptualization, Y.-M.W., S.-S.H. and E.-Y.H.; methodology, Y.-M.W. and S.-S.H.; software, Y.-M.W. and S.-S.H.; validation, Y.-M.W., S.-S.H. and E.-Y.H.; formal analysis, Y.-M.W. and S.-S.H.; investigation, Y.-M.W., C.-J.W. and E.-Y.H.; resources, Y.-M.W. and E.-Y.H.; data curation, Y.-M.W., J.-Y.C. and E.-Y.H.; writing-original draft preparation, Y.-M.W.; writing-review and editing, Y.-M.W. and E.-Y.H.; visualization, Y.-M.W. and E.-Y.H.; supervision, E.-Y.H. All authors have read and agreed to the published version of the manuscript.

Funding: This research received no external funding.

Institutional Review Board Statement: The study was conducted according to the guidelines of the Declaration of Helsinki, and approved by the Institutional Review Board of Chang Gung Medical Foundation (98-3760B approved on 7 January 2010).

Informed Consent Statement: Informed consent was obtained from all subjects involved in the study.

Data Availability Statement: The data presented in this study are available on request from the corresponding author. The data are not publicly available due to the nature of this research, participants of this study did not agree for their data to be shared publicly.

Acknowledgments: The authors acknowledge all participants and their families for their willingness to join this study. The authors appreciate the Biostatistics Center, Kaohsiung Chang Gung Memorial Hospital for their statistics work.

Conflicts of Interest: The authors declare no conflict of interest. 


\section{References}

1. Posner, J.B.; Chernik, N.L. Intracranial metastases from systemic cancer. Adv. Neurol. 1978, 19, 579-592. [PubMed]

2. Posner, J.B. Management of brain metastases. Rev. Neurol. 1992, 148, 477-487.

3. Tsao, M.N.; Xu, W.; Wong, R.K.; Lloyd, N.; Laperriere, N.; Sahgal, A.; Rakovitch, E.; Chow, E. Whole brain radiotherapy for the treatment of newly diagnosed multiple brain metastases. Cochrane Database Syst. Rev. 2018, 1, CD003869. [CrossRef] [PubMed]

4. Gaspar, L.; Scott, C.; Rotman, M.; Asbell, S.; Phillips, T.; Wasserman, T.; McKenna, W.G.; Byhardt, R. Recursive partitioning analysis (RPA) of prognostic factors in three Radiation Therapy Oncology Group (RTOG) brain metastases trials. Int. J. Radiat. Oncol. Biol. Phys. 1997, 37, 745-751. [CrossRef]

5. Weltman, E.; Salvajoli, J.V.; Brandt, R.A.; de Morais Hanriot, R.; Prisco, F.E.; Cruz, J.C.; de Oliveira Borges, S.R.; Wajsbrot, D.B. Radiosurgery for brain metastases: A score index for predicting prognosis. Int. J. Radiat. Oncol. Biol. Phys. 2000, 46, 1155-1161. [CrossRef]

6. Lorenzoni, J.; Devriendt, D.; Massager, N.; David, P.; Ruiz, S.; Vanderlinden, B.; Van Houtte, P.; Brotchi, J.; Levivier, M. Radiosurgery for treatment of brain metastases: Estimation of patient eligibility using three stratification systems. Int. J. Radiat. Oncol. Biol. Phys. 2004, 60, 218-224. [CrossRef]

7. Sperduto, P.W.; Berkey, B.; Gaspar, L.E.; Mehta, M.; Curran, W. A new prognostic index and comparison to three other indices for patients with brain metastases: An analysis of 1960 patients in the RTOG database. Int. J. Radiat. Oncol. Biol. Phys. 2008, 70, 510-514. [CrossRef]

8. Tsao, M.N.; Rades, D.; Wirth, A.; Lo, S.S.; Danielson, B.L.; Gaspar, L.E.; Sperduto, P.W.; Vogelbaum, M.A.; Radawski, J.D.; Wang, J.Z.; et al. Radiotherapeutic and surgical management for newly diagnosed brain metastasis(es): An American Society for Radiation Oncology evidence-based guideline. Pract. Radiat. Oncol. 2012, 2, 210-225. [CrossRef]

9. Achrol, A.S.; Rennert, R.C.; Anders, C.; Soffietti, R.; Ahluwalia, M.S.; Nayak, L.; Peters, S.; Arvold, N.D.; Harsh, G.R.; Steeg, P.S.; et al. Brain metastases. Nat. Rev. Dis. Primers 2019, 5, 5. [CrossRef]

10. Boire, A.; Brastianos, P.K.; Garzia, L.; Valiente, M. Brain metastasis. Nat. Rev. Cancer 2020, 20, 4-11. [CrossRef]

11. Nieder, C.; Grosu, A.L.; Spanne, O.; Andratschke, N.H.; Geinitz, H. Brain metastases in patients under 50 years of age: Retrospective analysis. Clin. Exp. Metastasis 2012, 29, 949-956. [CrossRef]

12. Akselrod, S.; Gordon, D.; Ubel, F.A.; Shannon, D.C.; Berger, A.C.; Cohen, R.J. Power spectrum analysis of heart rate fluctuation: A quantitative probe of beat-to-beat cardiovascular control. Science 1981, 213, 220-222. [CrossRef]

13. Camm, A.J.; Malik, M.; Bigger, J.T.; Breithardt, G.; Cerutti, S.; Cohen, R.J.; Coumel, P.; Fallen, E.L.; Kennedy, H.L.; Kleiger, R.E.; et al. Heart rate variability: Standards of measurement, physiological interpretation and clinical use. Task Force of the European Society of Cardiology and the North American Society of Pacing and Electrophysiology. Circulation 1996, 93, 1043-1065.

14. Tsuji, H.; Larson, M.G.; Venditti, F.J., Jr.; Manders, E.S.; Evans, J.C.; Feldman, C.L.; Levy, D. Impact of reduced heart rate variability on risk for cardiac events. The Framingham Heart Study. Circulation 1996, 94, 2850-2855. [CrossRef]

15. Sato, A.; Sato, Y.; Uchida, S. Regulation of cerebral cortical blood flow by the basal forebrain cholinergic fibers and aging. Auton. Neurosci. 2002, 96, 13-19. [CrossRef]

16. Gidron, Y.; Perry, H.; Glennie, M. Does the vagus nerve inform the brain about preclinical tumours and modulate them? Lancet Oncol. 2005, 6, 245-248. [CrossRef]

17. Kleiger, R.E.; Miller, J.P.; Bigger, J.T., Jr.; Moss, A.J. Decreased heart rate variability and its association with increased mortality after acute myocardial infarction. Am. J. Cardiol. 1987, 59, 256-262. [CrossRef]

18. Tuininga, Y.S.; van Veldhuisen, D.J.; Brouwer, J.; Haaksma, J.; Crijns, H.J.; Man in't Veld, A.J.; Lie, K.I. Heart rate variability in left ventricular dysfunction and heart failure: Effects and implications of drug treatment. Br. Heart J. 1994, 72, 509-513. [CrossRef] [PubMed]

19. Wang, Y.M.; Wu, H.T.; Huang, E.Y.; Kou, Y.R.; Hseu, S.S. Heart rate variability is associated with survival in patients with brain metastasis: A preliminary report. Biomed. Res. Int. 2013, 2013, 503421. [CrossRef]

20. Benichou, T.; Pereira, B.; Mermillod, M.; Tauveron, I.; Pfabigan, D.; Maqdasy, S.; Dutheil, F. Heart rate variability in type 2 diabetes mellitus: A systematic review and meta-analysis. PLoS ONE 2018, 13, e0195166. [CrossRef] [PubMed]

21. Kloter, E.; Barrueto, K.; Klein, S.D.; Scholkmann, F.; Wolf, U. Heart Rate Variability as a Prognostic Factor for Cancer Survival-A Systematic Review. Front. Physiol. 2018, 9, 623. [CrossRef]

22. De Couck, M.; van Brummelen, D.; Schallier, D.; De Greve, J.; Gidron, Y. The relationship between vagal nerve activity and clinical outcomes in prostate and non-small cell lung cancer patients. Oncol. Rep. 2013, 30, 2435-2441. [CrossRef]

23. De Couck, M.; Caers, R.; Spiegel, D.; Gidron, Y. The Role of the Vagus Nerve in Cancer Prognosis: A Systematic and a Comprehensive Review. J. Oncol. 2018, 2018, 1236787. [CrossRef]

24. De Couck, M.; Mravec, B.; Gidron, Y. You may need the vagus nerve to understand pathophysiology and to treat diseases. Clin. Sci. 2012, 122, 323-328. [CrossRef]

25. Ohira, H.; Matsunaga, M.; Osumi, T.; Fukuyama, S.; Shinoda, J.; Yamada, J.; Gidron, Y. Vagal nerve activity as a moderator of brain-immune relationships. J. Neuroimmunol. 2013, 260, 28-36. [CrossRef]

26. Chiang, J.K.; Koo, M.; Kuo, T.B.; Fu, C.H. Association between cardiovascular autonomic functions and time to death in patients with terminal hepatocellular carcinoma. J. Pain Symptom Manag. 2010, 39, 673-679. [CrossRef] [PubMed]

27. Lauer, M.S. Autonomic function and prognosis. Cleve Clin. J. Med. 2009, 76 (Suppl. 2), S18-S22. [CrossRef] [PubMed] 
28. Kim, D.H.; Kim, J.A.; Choi, Y.S.; Kim, S.H.; Lee, J.Y.; Kim, Y.E. Heart rate variability and length of survival in hospice cancer patients. J. Korean Med. Sci. 2010, 25, 1140-1145. [CrossRef] [PubMed]

29. De Couck, M.; Marechal, R.; Moorthamers, S.; Van Laethem, J.L.; Gidron, Y. Vagal nerve activity predicts overall survival in metastatic pancreatic cancer, mediated by inflammation. Cancer Epidemiol. 2016, 40, 47-51. [CrossRef] [PubMed]

30. Guo, Y.; Koshy, S.; Hui, D.; Palmer, J.L.; Shin, K.; Bozkurt, M.; Yusuf, S.W. Prognostic Value of Heart Rate Variability in Patients with Cancer. J. Clin. Neurophysiol. 2015, 32, 516-520. [CrossRef]

31. Hoca, A.; Yildiz, M.; Ozyigit, G. Evaluation of the effects of mediastinal radiation therapy on autonomic nervous system. Med. Oncol. 2012, 29, 3581-3586. [CrossRef] [PubMed]

32. Chang, E.L.; Wefel, J.S.; Hess, K.R.; Allen, P.K.; Lang, F.F.; Kornguth, D.G.; Arbuckle, R.B.; Swint, J.M.; Shiu, A.S.; Maor, M.H.; et al. Neurocognition in patients with brain metastases treated with radiosurgery or radiosurgery plus whole-brain irradiation: A randomised controlled trial. Lancet Oncol. 2009, 10, 1037-1044. [CrossRef]

33. Tallet, A.V.; Azria, D.; Barlesi, F.; Spano, J.P.; Carpentier, A.F.; Goncalves, A.; Metellus, P. Neurocognitive function impairment after whole brain radiotherapy for brain metastases: Actual assessment. Radiat. Oncol. 2012, 7, 77. [CrossRef] [PubMed]

34. Brown, P.D.; Ahluwalia, M.S.; Khan, O.H.; Asher, A.L.; Wefel, J.S.; Gondi, V. Whole-Brain Radiotherapy for Brain Metastases: Evolution or Revolution? J. Clin. Oncol. 2018, 36, 483-491. [CrossRef]

35. In Laws \& Regulations, National Health Insurance Administration, Ministry of Health and Welfare. Available online: https: / / www.nhi.gov.tw/english/Content_List.aspx?n=A7354F4F704B6377\&topn=A7354F4F704B6377 (accessed on 20 July 2021). 